\title{
Propolis improves pregnancy outcomes and placental oxidative stress status in streptozotocin-induced diabetic rats
}

\author{
Umar Zayyanu Usman', Ainul Bahiyah Abu Bakar ${ }^{2}$ and Mahaneem Mohamed ${ }^{2,3^{*}}$ (D)
}

\begin{abstract}
Background: This study assessed the effects of propolis alone or combined with insulin on maternal status, pregnancy outcomes and placental oxidative stress in streptozotocin-induced diabetic rats.

Methods: Forty female rats were randomly assigned into five groups ( $n=8 /$ group) i.e. non-DM (non-diabetes), DM (diabetes), DM + Propolis (diabetes on propolis orally); DM + Insulin (diabetes on insulin subcutaneously) and DM + Combined (diabetes on propolis and insulin) groups. Propolis and insulin were given at $300 \mathrm{mg} / \mathrm{kg} / \mathrm{day}$ orally and $5.0 \mathrm{lU} / \mathrm{kg} /$ day subcutaneously, respectively, for 4 weeks.

Results: Fasting blood glucose, conception period, implantation losses, foetal blood glucose and placental oxidative stress markers such as malonaldehyde and protein carbonyl were significantly higher while maternal weight gain, foetal body weight and total antioxidant capacity were significantly lower in DM group compared with non-DM group. These changes were significantly improved in rats treated with propolis or insulin alone with greater significant effects in rats treated with both propolis and insulin.
\end{abstract}

Conclusion: This study may suggest the protective effects of propolis against DM-induced impaired pregnancy outcomes and placental oxidative stress with greater effects when combined with insulin.

Keywords: Diabetes, Propolis, Pegnancy outcomes, Oxidative stress

\section{Background}

There is an increase in the prevalence of diabetes mellitus (DM) which is projected to increase up to 642 million by 2040. Its effect on the patient socio-economy, physical and medical state has become a major concern globally [1]. Diabetes-induced hyperglycaemic changes have been found to be potentially detrimental to intrauterine foetal development [2]. In an experimental rat, maternal hyperglycaemia-exposed foetus has septal hypertrophy [3]. Moreover, previous study reveals that mothers with pre-gestational DM are more likely to have a baby with some congenital malformations compared with normal healthy women who never have diabetes [4]. Some factors are correlated with foetal anomalies in

\footnotetext{
* Correspondence: mahaneem@usm.my

${ }^{2}$ Department of Physiology School of Medical Sciences, Universiti Sains Malaysia, 16150 Kubang Kerian, Kelantan, Malaysia

${ }^{3}$ Unit of Integrative Medicine, School of Medical Sciences, Universiti Sains

Malaysia, 16150 Kubang Kerian, Kelantan, Malaysia

Full list of author information is available at the end of the article
}

the diabetic mother which include age, obesity, motivation, educational status, duration of the disease, compliance with diet and medications [5]. Furthermore, oxidative markers such as 8-isoprostane and protein carbonyl levels are significantly higher in placentae obtained from women with gestational DM compared to healthy pregnant women. These data demostrate the presence of oxidative stress in the placentae of women with hyperglycaemia which may potentially lead to foetal compromise [6]. Antioxidants prevent or remove oxidative damage to a target molecule through donating an electron to stabilise the free radical [7]. Consumption of natural products with antioxidants such as flavonoid and phenolic acids improves oxidant-antioxidant status and decreases the risk of developing DM complications [8]. Superoxide anion radical $\left(\mathrm{O}_{2}^{-}\right)$is one of the strongest reactive oxygen species (ROS) among the radicals that are generated after oxygen is taken into living cells. This $\mathrm{O}^{-}{ }_{2}$ can change to other harmful ROS, which lead to 
oxidative stress and implicated in the aetiology of many diseases including DM [9].

Brazilian propolis at doses of 100, 200 and $300 \mathrm{mg} / \mathrm{kg}$ body weight for 40 days improve body and kidney weights, serum glucose, lipid profile, malondialdehyde (MDA) and renal function in diabetic male rats [10]. Saudi Arabian propolis at $200 \mathrm{mg} / \mathrm{kg} /$ day reduces fasting blood glucose (FBG) and MDA levels, and preserves pancreatic islet of Langerhans in diabetic rats and alleviates diabetic signs [11]. Turkey propolis at doses of 0.2, 0.4 and $0.6 \mathrm{mg} / \mathrm{ml}$ per day for 28 days significantly improve cryopreservation and fertilization ability in fish semen [12]. Malaysian propolis at $300 \mathrm{mg} / \mathrm{kg} /$ day for 4 weeks has shown antihyperglycaemic property in diabetic rats [13]. However, to date, it is known whether propolis may also ameliorate hyperglycaemia-induced impaired pregnancy outcomes and placental oxidative stress in DM. Hence, the objective of the study was to determine the effects of propolis alone or combined with insulin on maternal status, pregnancy outcomes and placental oxidative stress status in streptozotocin-induced diabetic female rats.

\section{Methods}

\section{Propolis preparation}

Raw propolis of stingless bee (Heterotrigona itama) was purchased from the local beekeeper in Kelantan, Malaysia which was collected during dry season (AprilJune in 2015) and stored at $-40^{\circ} \mathrm{C}$. Briefly, raw propolis $(30 \mathrm{~g})$ was washed with distilled water, frozen at $-80^{\circ} \mathrm{C}$ and ground into powder. Then, it was mixed vigorously with $100 \mathrm{~mL}$ of $70 \%(\mathrm{v} / \mathrm{v})$ ethanol at room temperature on a shaker for $6 \mathrm{~h}$ daily for 7 days. It was then filtered, concentrated and freeze-dried or lyophilized to remove ethanol and water to obtain propolis sample to be used in the study [13].

\section{Experimental design}

Forty female Sprague Dawley rats of age 8 to 10 weeks (190-220 g) were used. The animals were obtained from the Laboratory Research Unit, Health Campus, Universiti Sains Malaysia. They were exposed to 12-h light, 12h dark cycle at $22-24^{\circ} \mathrm{C}$, and given water and food ad libitum. The animals were randomly assigned into 5 groups ( $n=8$ rats per group) as follows: (i) non-DM group (Healthy rats on $1 \mathrm{~mL}$ distilled water orally), (ii) DM group (Diabetic rats on $1 \mathrm{~mL}$ distilled water orally) (iii) $\mathrm{DM}+$ Propolis (Diabetic rats on $300 \mathrm{mg} / \mathrm{kg} /$ day propolis orally) (iv) DM + insulin group (Diabetic rats on $5.0 \mathrm{IU} / \mathrm{kg} /$ day insulin subcutaneously) and (v) DM + Combined group (Diabetic rats on $300 \mathrm{mg} / \mathrm{kg} /$ day propolis orally and 5.0 $\mathrm{UI} / \mathrm{kg} /$ day subcutaneously). DM was induced using single intraperitoneal injection of streptozotocin (STZ; SigmaAldrich Co., St Louis, USA) at $60 \mathrm{mg} / \mathrm{kg}$ body weight after fasting for $16 \mathrm{~h}$ overnight. Diabetes was confirmed after $48 \mathrm{~h}$ of STZ injection [13]. Animals with FBG level of $\geq 200 \mathrm{mg} / \mathrm{dl}$ (Digital Glucometer, Lifescan Inc. Milpitas, USA) were considered as having DM and used. All treatments were given for 4 weeks. After a week of treatment, each female rat was mated overnight at pro-oestrous with a proven fertile male rat to achieve pregnancy and sperm positive smear was considered as Day 1 of pregnancy. Initial and final FBG levels, conception period and maternal weight gain were recorded.

On Day 21 of pregnancy, all female rats were fasted overnight, anaesthetised by intraperitoneal injection of $90 \mathrm{mg} / \mathrm{kg}$ ketamine and $5 \mathrm{mg} / \mathrm{kg}$ xylazine. Laparotomy was performed on each rat and blood was taken from the heart for biochemical analysis. Then the rats were sacrificed by cervical dislocation. Pregnancy outcomes such as percentages of resorption and implantation loss, number of live and dead foetuses, foetal and placental weights and foetal fasting blood glucose level were assessed. Placental oxidative stress status such as MDA and protein carbonyl (PCO), and total antioxidant capacity (TAC) were assessed using commercial kits (BioAssay Systems. California, USA).

This study was approval by the Animal Ethics Committee of Universiti Sains Malaysia [Animal Ethics Approval/2013/(90)(503) USM] and carried out in accordance with the National Institute of Health Guideline for the care and use of laboratory animals.

\section{Statistical analysis}

All numerical data are expressed as mean and standard deviation (SD). Statistical analysis was performed using Instat. Exe version 3.1. (Charleswork Publishing Services Ltd. Deighton, Huddersfield, UK). One way analysis of variance (ANOVA) followed by Turkey-Kramer test was used to assess the differences among means for normally distributed data and $P<0.05$ was considered as statistically significant.

\section{Results}

\section{Effects on maternal parameters}

Final FBG level was significantly higher in DM compared with non-DM group. The final FBG levels in DM + Propolis, DM + Insulin and DM + Combined groups were significantly lower compared with DM group but significantly higher than non-DM group. However, the final FBG in DM + Combined group was significantly lower than DM + P group (Table 1).

Conception period was significantly longer in DM group compared with non-DM group. It was significantly shorter in DM + Combined group compared with DM group. There were no significant differences for conception period in DM + Propolis, DM + Insulin and 
Table 1 Effects of administration of propolis on fasting blood glucose level and conception period of pregnant streptozotocininduced diabetic rats

\begin{tabular}{llll}
\hline Groups & Initial FBG level $(\mathrm{mg} / \mathrm{dL})$ & Final FBG level $(\mathrm{mg} / \mathrm{dL})$ & Conception period (hours) \\
\hline Non-DM & $89.25(1.75)$ & $89.88(0.64)$ & $27.00(8.49)$ \\
DM & $404.13(28.72)^{\mathrm{a}}$ & $568.00(48.07)^{\mathrm{a}}$ & $81.00(54.33)^{\mathrm{a}}$ \\
DM + Propolis & $415.38(11.87)^{\mathrm{a}}$ & $274.13(40.66)^{\mathrm{a}, \mathrm{b}}$ & $42.00(27.96)$ \\
DM + Insulin & $413.75(14.48)^{\mathrm{a}}$ & $242.13(61.48)^{\mathrm{a}, \mathrm{b}}$ & $42.00(27.96)$ \\
DM + Combined & $424.63(21.78)^{\mathrm{a}}$ & $191.88(18.50)^{\mathrm{a}, \mathrm{b}, \mathrm{c}}$ & $33.00(17.86)^{\mathrm{b}}$ \\
\hline
\end{tabular}

Data are presented as mean (standard deviation), ( $n=8$ per group). DM: diabetes mellitus, Combined: Propolis and insulin, FBG: fasting blood glucose. ${ }^{\mathrm{a}} P<0.05$ compared with negative control, non-DM group; ${ }^{b} P<0.05$ compared with DM group; ${ }^{c} P<0.05$ compared with DM + Propolis group (ANOVA followed by Turkey-Kramer post-hoc test)

$\mathrm{DM}+$ Combined groups compared to non-DM groups (Table 1). Maternal body weight gain was significantly lower in DM and DM + Propolis groups compared with non-DM group. However, the maternal body weight gain was significantly higher in DM + Propolis, $\mathrm{DM}+$ Insulin and $\mathrm{DM}+$ Combined groups compared with DM group (Table 2).

\section{Effects on pregnancy outcomes}

Pre- and post-implantation losses were significantly higher while total number of foetuses was significantly lower in DM group compared with non-DM group. However, pre-implantation loss was significantly lower in DM + Insulin and DM + Combined groups compared to DM group. Post-implantation loss was significantly lower while total number of foetuses was significantly higher in DM + Propolis, DM + Insulin and DM + Combined groups compared to DM group (Table 3). All foetuses exhibited normal physical characteristics with no gross congenital abnormality. No protrusion of any of the organs, and no signs of cleft were seen in lips and palate, and all the foetuses showed normal size, shape and position of tail.

\section{Effects on Foetal blood glucose level and body weight} Foetal body weight was significantly lower in DM and $\mathrm{DM}+$ Propolis groups compared with non-DM group. It was significantly higher in DM + Combined group compared with DM group. Foetal blood glucose was

Table 2 Effect of administration of propolis on maternal body weight gain of pregnant streptozotocin-induced diabetic rats

\begin{tabular}{ll}
\hline Groups & Maternal body weight gain $(\mathrm{g})$ \\
\hline Non-DM & $155.25(37.06)$ \\
DM & $61.00(16.40)^{\mathrm{a}}$ \\
DM + Propolis & $111.75(33.55)^{\mathrm{a}, \mathrm{b}}$ \\
DM + Insulin & $112.75(27.00)^{\mathrm{b}}$ \\
DM + Combined & $140.88(29.67)^{\mathrm{b}}$
\end{tabular}

Data are represented as mean (standard deviation), ( $n=8$ per group). DM: diabetes mellitus, Combined: Propolis and insulin. ${ }^{a} P<0.05$ compared with non-DM group, ${ }^{\mathrm{b}} P<0.05$ compared with DM group (ANOVA followed by Turkey-Kramer post-hoc test) significantly higher in DM, DM + Propolis and DM + Insulin groups compared with non-DM group. Blood glucose was significantly lower in DM + Propolis, DM + Insulin and DM + Combined groups compared with DM group (Table 4).

\section{Effects on placental weight and oxidative stress status in diabetic rats}

No significant differences in relative placental weight were evident between all the experimental groups (Table 5). Placental MDA and PCO levels were significantly higher while TAC level was significantly lower in DM group compared with non-DM group. However, MDA and PCO levels were significantly lower while TAC level was significantly higher in DM + Propolis, $\mathrm{DM}+$ Insulin and $\mathrm{DM}+$ Combined groups compared with DM group. TAC was significantly higher in DM + Combined group compared with $\mathrm{DM}+$ Insulin group (Table 6).

\section{Discussion}

In this study, we investigated the effects of propolis alone as monotherapy or in combination with insulin on maternal status, pregnancy outcomes and placental oxidative stress status in diabetic female rats. Considering that DM is a disorder of multiple etiologies, monotherapy with an antihyperglycaemic agent may not be effective [14]. Initial FBG levels of all the STZ-induced diabetic rats were greater than $200 \mathrm{mg} / \mathrm{dL}$ and significantly higher than non-DM group prior to the commencement of treatments showing the establishment of diabetic animal model. Final FBG in DM+Propolis group was comparable with $\mathrm{DM}+$ insulin group which may indicate that propolis and insulin are equally effective to produce a comparable antihyperglycaemic effect. The antihyperglycaemic effect of $300 \mathrm{mg} / \mathrm{kg} /$ day Malaysian propolis for 4 weeks found in the present study is in line with the findings on propolis from other countries. For instance, Nigerian propolis at doses of 200 and 300 $\mathrm{mg} / \mathrm{kg} /$ day for 4 weeks [15] and Saudi Arabian propolis at a dose of $300 \mathrm{mg} / \mathrm{kg} /$ day for 2 weeks significantly reduce FBG level in DM male rats [11]. Moreover, 
Table 3 Effects of administration of propolis on implantation loss and number of foetus of pregnant streptozotocin-induced diabetic rats

\begin{tabular}{llll}
\hline Groups & Pre-implantation Loss (\%) & Post-implantation Loss (\%) & Number of foetus (n) \\
\hline Non-DM & $9.82(7.80)$ & $8.85(5.78)$ & $12.50(1.69)$ \\
DM & $38.69(18.93)^{\mathrm{a}}$ & $42.14(21.55)^{\mathrm{a}}$ & $5.25(2.82)^{\mathrm{a}}$ \\
DM + Propolis & $21.44(12.53)$ & $11.50(7.82)^{\mathrm{b}}$ & $9.75(2.61)^{\mathrm{b}}$ \\
DM + Insulin & $19.87(7.52)^{\mathrm{b}}$ & $14.45(16.05)^{\mathrm{b}}$ & $9.13(1.81)^{\mathrm{b}}$ \\
DM + Combined & $19.88(10.36)^{\mathrm{b}}$ & $14.57(17.38)^{\mathrm{b}}$ & $9.13(3.87)^{\mathrm{b}}$ \\
\hline
\end{tabular}

Data are presented as mean (standard deviation), ( $n=8$ per group). DM: diabetes mellitus, Combined: Propolis and insulin. ${ }^{\text {a }} P<0.05$ compared with non-DM group, ${ }^{b} P<0.05$ compared with DM group (ANOVA followed by Turkey-Kramer post-hoc test)

Egyptian and Brazilian propolis at the dose of $300 \mathrm{mg} /$ $\mathrm{kg} /$ day [16] and $900 \mathrm{mg} / \mathrm{kg} /$ day [17], respectively, for 2 weeks significantly reduce FBG level in DM male rats, which further support propolis as a potential antihyperglycaemic agent possibly due to the ability of polyphenols in propolis to stimulate insulin secretion by the remaining islets cells with normal function [11]. Furthermore, the antihyperglycaemic effect was found to be more pronounced in DM + Combined group compared with $\mathrm{DM}+$ propolis and $\mathrm{DM}+$ Insulin groups suggesting that propolis in combination with insulin may produce greater antihyperglycaemic effect than propolis or insulin alone as mono-therapy.

DM may alter reproductive functions in human subject [18]. The longer conception period in DM group compared to non-DM group may be due to the presence of hyperglycaemia which is associated with reduced libido as previously shown in DM male rats [19]. However, the conception period was significantly lower in $\mathrm{DM}+$ Combined group, not in DM + Propolis and DM + Insulin groups, compared with DM group. These findings may indicate that propolis combined with insulin is able to improve conception period which could be attributed to the concomitant greater improved FBG level found in $\mathrm{DM}+$ Combined group. The significant improved maternal body weight gain in $\mathrm{DM}+$ propolis, DM+Insulin and DM+Combined groups could

Table 4 Effects of administration of propolis on foetal body weight and blood glucose level of pregnant streptozotocininduced diabetic rats

\begin{tabular}{lll}
\hline Groups & Foetal body weight $(\mathrm{g})$ & $\begin{array}{l}\text { Foetal blood glucose } \\
\text { level }(\mathrm{mg} / \mathrm{dL})\end{array}$ \\
\hline Non-DM & $5.37(0.34)$ & $98.88(10.95)$ \\
DM & $4.31(0.61)^{\mathrm{a}}$ & $429.13(118.74)^{\mathrm{a}}$ \\
DM + Propolis & $4.66(0.52)^{\mathrm{a}}$ & $216.00(50.24)^{\mathrm{a}, \mathrm{b}}$ \\
DM + Insulin & $4.83(0.36)$ & $201.75(56.94)^{\mathrm{a}, \mathrm{b}}$ \\
DM + Combined & $5.07(0.51)^{\mathrm{b}}$ & $148.63(33.26)^{\mathrm{b}}$
\end{tabular}

Data are presented as mean (standard deviation), ( $n=8$ per group). DM: diabetes mellitus, Combined: Propolis and insulin. ${ }^{a} P<0.05$ compared with non-DM group, ${ }^{\mathrm{b}} P<0.05$ compared with DM group (ANOVA followed by Turkey-Kramer post-hoc test) also be attributed to the antihyperglycaemic effect of propolis and insulin. The improved maternal body weight in $\mathrm{DM}+$ propolis is in accordance with previous study [13] and propolis has been shown to improve insulin level in diabetic rats [11]. This in turn may improve maternal body weight as insulin is known to exert an anabolic effect through stimulating protein synthesis and inhibiting protein degradation and lipolysis [20].

The significantly higher implantation losses might explain for the lower number of foetus found in DM group compared to non-DM group. These findings support the fact that chronic exposure to hyperglycaemia during early pregnancy is associated with implantation loss [21]. Nevertheless, failure of embryo implantation may cause morphological alterations of embryo that eventually interferes with the implantation and promotes embryo lethality. Additionally, failure of implantation is also resulted from disturbance in tubal transport and subsequent interference in the time of blastocyst arrival in the uterus [22]. These findings support the fact that DM in the first trimester of pregnancy is detrimental to blastocyst and embryo formation [23]. Pre-implantation loss was significantly lower in DM+insulin and DM+Combined group compared to DM group which may suggest that propolis in combination with insulin has greater effect in reducing pre-implantation loss as compared to propolis alone. However, the significantly improved post-implantation loss and number of foetus

Table 5 Effect of administration of propolis on relative placental weight of pregnant streptozotocin-induced diabetic rats

\begin{tabular}{ll}
\hline Groups & Relative placental weight (\%) \\
\hline Non-DM & $0.170(0.023)$ \\
DM & $0.154(0.018)$ \\
DM + Propolis & $0.165(0.025)$ \\
DM + Insulin & $0.167(0.005)$ \\
DM + Combined & $0.163(0.018)$ \\
\hline
\end{tabular}

Data are presented as mean (standard deviation), ( $n=8$ per group). DM: diabetes mellitus, Combined: Propolis and insulin. No significant difference observed between all groups (ANOVA) 
Table 6 Effects of administration of propolis on placental oxidative stress markers of pregnant streptozotocin-induced diabetic rats

\begin{tabular}{llll}
\hline Groups & Malonaldehyde $(\mathrm{nmol} / \mathrm{mg}$ protein) & Protein carbonyl (nmol/mg protein) & Total antioxidant capacity (nmol/mg protein) \\
\hline Non-DM & $0.844(0.173)$ & $1.196(0.039)$ & $0.393(0.046)$ \\
DM & $3.322(0.442)^{\mathrm{a}}$ & $3.510(0.331)^{\mathrm{a}}$ & $0.158(0.029)^{\mathrm{a}}$ \\
DM + Propolis & $1.147(0.456)^{\mathrm{b}}$ & $2.087(0.339)^{\mathrm{a}, \mathrm{b}}$ & $0.249(0.028)^{\mathrm{a}, \mathrm{b}}$ \\
DM + Insulin & $1.116(0.220)^{\mathrm{b}}$ & $2.496(0.428)^{\mathrm{a}, \mathrm{b}}$ & $0.215(0.018)^{\mathrm{a}, \mathrm{b}}$ \\
DM + Combined & $1.026(0.338)^{\mathrm{b}}$ & $1.967(0.371)^{\mathrm{a}, \mathrm{b}, \mathrm{c}}$ & $0.295(0.040)^{\mathrm{a}, \mathrm{b}, \mathrm{d}}$
\end{tabular}

Data are presented as mean (standard deviation), ( $n=8$ per group). DM: diabetes mellitus, Combined: Propolis and insulin, FBG: fasting blood glucose. ${ }^{a} P<0.05$ compared with non-DM group; ${ }^{b} P<0.05$ compared with DM group; ${ }^{c} P<0.05$ compared with DM + Propolis group, ${ }^{d} P<0.05$ compared with $D M+$ Insulin group (ANOVA followed by Turkey-Kramer post-hoc test)

might suggest the comparable action of propolis, insulin or in combination possibly via their antihyperglycaemic effect to prevent post-implantation loss in this diabetic animal model. These findings are similar with a study using an essential acid taurine that significantly improves pregnancy outcomes and protects both the dam and embryos during pregnancy in diabetic rat [23]. The findings on normal gross morphology of the foetuses are in contrast with a few studies in which prenatal stress in rodents is associated with the risk of developing congenital abnormalities [24]. The external evaluation in the present study might suggest that propolis does not cause any foetal gross malformation and assessment on internal organs is, however, suggested in further study.

Foetal blood glucose level was significantly higher in DM group and this could be associated with STZ-induced maternal hyperglycaemia and hypoinsulinaemia despite normal beta cells function in the foetus. However, foetal blood glucose was significantly improved when treated with propolis or insulin without significant change in foetal body weight. The reduction in foetal birth weight in diabetes may be associated with the detrimental effect of maternal hyperglycaemia leading to intrauterine growth retardation $[25,26]$. However, both foetal blood glucose and foetal body weight were significantly improved in DM + Combined group which could be attributed to the improved maternal FBG and weight.

Placental MDA and PCO levels were significantly lower while placental TAC level was significantly higher in $\mathrm{DM}+$ propolis, $\mathrm{DM}+$ Insulin and $\mathrm{DM}+$ Combined groups compared to DM group which may suggest the ability of propolis and insulin to reduce placental oxidative stress. This finding may support previous study showing the antioxidant potential of Iranian propolis in DM rats [27] and the greater beneficial effects in $\mathrm{DM}+$ Combined group may suggest the synergistic effect of propolis and insulin. The reduced placental oxidative stress could be indirectly due to the antihyperglycaemic action of propolis and insulin as there is a presence of placental oxidative stress in mother with hyperglycaemia [6]. Apart from that, the antioxidant effect of propolis found in the present study could also partly due to the direct synergistic actions of flavonoids and phenols, which have antioxidant property, that present in Malaysian propolis [28].

\section{Conclusion}

In conclusion, this study may suggest the protective effects of propolis against DM-induced impaired pregnancy outcomes and placental oxidative stress with greater effects when combined with insulin which could be partly due to the synergistic effect of some of its phytochemical constituents. Apart from supporting the traditional belief on the beneficial effect of propolis on health, further studies are suggested to determine its molecular mechanism of action and its possible role in protecting or reducing complications of DM in other organs.

\section{Abbreviations \\ ANOVA: One way analysis of variance; DM: Diabetes mellitus; FBG: Fasting blood glucose; MDA: Malondialdehyde; O-2: Superoxide anion radical; PCO: Protein carbonyl; SD: Standard deviation; STZ: Streptozotocin; TAC: Total antioxidant capacity}

\section{Acknowledgments}

Authors wish to acknowledge Universiti Sains Malaysia Research University Grant (1001/PPSP/813072) for supporting this study and Malaysian International Scholarship (MIS) for supporting the first author.

\section{Funding}

This work was supported by the Universiti Sains Malaysia Research University Grant (1001/PPSP/813072) and the first author was supported by Malaysian International Scholarship (MIS).

\section{Availability of data and materials}

The datasets generated and/or analysed during the current study are not publicly available due to Research Data Management and Intellectual Property Policies of Universiti Sains Malaysia that prevent research data sharing in public repositories, but are available from the corresponding author on reasonable request.

\section{Authors' contributions}

UZU (1st author) carried out all the lab work, the analysis of the data and drafted the manuscript. ABAB (2nd author) and MM (3rd and corresponding author) participated in the design of the study and finalised the manuscript. All authors read and approved the manuscript before submission.

\section{Ethics approval}

This study was approval by the Animal Ethics Committee of Universiti Sains Malaysia [Animal Ethics Approval/2013/(90)(503) USM]. 


\section{Competing interests}

The authors declare that they have no competing interests.

\section{Publisher's Note}

Springer Nature remains neutral with regard to jurisdictional claims in published maps and institutional affiliations.

\section{Author details}

'Department of Physiology, College of Health Sciences, Usman Danfodiyo University, Sokoto, Nigeria. ${ }^{2}$ Department of Physiology School of Medical Sciences, Universiti Sains Malaysia, 16150 Kubang Kerian, Kelantan, Malaysia. ${ }^{3}$ Unit of Integrative Medicine, School of Medical Sciences, Universiti Sains Malaysia, 16150 Kubang Kerian, Kelantan, Malaysia.

\section{Received: 10 June 2018 Accepted: 27 November 2018}

Published online: 05 December 2018

\section{References}

1. International Diabetes Federation (IDF) 7th Edition Atlas, IDF revision. http:// www.idf.org/diabetesatlas. 2016. Accessed 25 Feb 2017.

2. The HAPO Study Cooperative Research Group. Hyperglycemia and adverse pregnancy outcomes. N Engl J Med. 2008;358:1991-2002.

3. Gordon E, Reinking E, Hu S. Maternal hyperglycemia directly and rapidly induced cardiac septal overgrowth in fetal rats. J Diab Res. 2015. Article ID 479565, 11 pages. doi.org/https://doi.org/10.1155/2015/479565.

4. Correa A, Gilboa SM, Besser LM. Diabetes mellitus and birth defects. Am J Obstet Gynecol. 2008;199(3):237 e1-237.e9.

5. Dalewitz J, Khan N, Hershey CO. Barriers to control of blood glucose in diabetes mellitus. Am J Med Qual. 2000;15(1):16-25.

6. Coughlan MT, Vervaart PP, Permezel M, Georgioua HM, Rice GE. Altered placental oxidative stress status in gestational diabetes mellitus. Placenta. 2004;25:78-84.

7. Chiuailaf RH, Contreras PA, Wittwer FG. Pathogenesis of oxidative stress: Consequences and evaluation in animal health. Vet Mex. 2002;33(3):265-83.

8. Sheweita SA, Mashaly S, Newairy AA. Changes in oxidative stress and antioxidant enzyme activities in streptozotocin-induced diabetes mellitus in rats: Role of Alhagi maurorum extracts. Oxid Med Cel Long. 2016. Article ID 5264064, 8 pages. doi.org/https://doi.org/10.1155/2016/5264064.

9. Rehman K, Akash MSH. Mechanism of generation of oxidative stress and pathophysiology of type 2 diabetes mellitus: how are they interlinked? J Cell Biochem. 2017;118(11):3577-85.

10. Abo-Salem OM, El-Edel RH, Harisa GE, El-Halawany N, Ghonaim MM. Experimental diabetic nephropathy can be prevented by propolis: effect on metabolic disturbances and renal oxidative parameters. Pak J Pharm Sci. 2009;22(2):205-10.

11. Al-Hariri MT, Eldin TA, Al-Harb MM. Protective effect and potential mechanisms of propolis on streptozotocin-induced diabetic rats. J Taibah Univ Med Sci. 2016;11(1):7-12.

12. Öğretmen $F$, İnanan BE, Öztürk M. Protective effects of propolis on cryopreservation of common carp (Cyprinus carpio) sperm. Cryobiology. 2014;68(1):107-12.

13. Usman UZ, Bakar ABA, Mohamed M. Phytochemical composition and activity against hyperglycemia of Malaysian propolis in diabetic rats. Biomed Res. 2016;27(1):46-51.

14. Ismail-Beigi F, Craven T, Banerji MA, et al. Effect of intensive treatment of hyperglycaemia on microvascular outcomes in type 2 diabetes: an analysis of the CCORD randomised trial. Lancet. 2010;376(9739):419-30.

15. Babatunde IR, Abdulbasit AA, Oladayo MI, Olasile OI. Hepatoprotective and pancreatoprotective properties of the ethanolic extract of Nigerian propolis. J Intercult Ethnopharmacol. 2015;4(2):102-8.

16. Al-Saeed HF, Mohamed NY. The possible therapeutic effects of propolis on osteoporosis in diabetic male rats. Nature Sci. 2015;13(3):136-40.

17. Zhao L, Pu L, Wei J, Li J, Wu J, Xin Z, Gao W. Brazillian green propolis improves antioxidant function in patient with type 2 diabetes mellitus. Int J Environ Res Public Health. 2016;13(5):490-8.

18. American Diabetes Association (ADA). Standards of medical care in diabetes. Diabetes care, Summary of revision. 2016. http://www.diabetes. org/diabetescare. Accessed 3 Feb 2017.

19. Alves MG, Martins AD, Rato L, Moreira PI, Socorro S, Oliveira PF. Molecular mechanisms beyond glucose transport in diabetes-related male infertility. Biochim Biophys Acta. 2013;1832(5):626-35.
20. Dimitriadis G, Mitrou P, Lambadiari V, Maratou E, Raptis SA. Insulin effects in muscle and adipose tissue. Diabetes Res Clin Pract. 2011;93(Suppl 1):52-9.

21. Thompson J, Cadmium BJ. Toxic effects on the reproductive system and the embryo. Reprod Toxicol. 2008:25(3):304-15.

22. Albaghdadi AJ, Kan FW. Endometrial receptivity defects and impaired implantation in diabetic NOD mice. Biol Reprod. 2012;87(2):1-16.

23. Shivananjappa MM, Muralidhara. Taurine attenuates maternal and embrynic oxidative stress in a streptozotocin-diabetic rat model. Reprod BioMed Online. 2012;24(5):558-66

24. Paris JJ, Frye CA. Juvenile offspring of rats exposed to restraint stress in late gestation have impaired cognitive performance and dysregulated progestogen formation. Intern J Bio Stress. 2011;14(1):23-32.

25. Inhasz Kiss AC, Woodside B, Sinzato YK, Bernardi MM, Kempinas WDG, Anselmo-Franci JA, Damasceno DC. Neonatally induced mild diabetes: influence on development, behavior and reproductive function of female Wistar rats. Diabetol Metab Syndr. 2013;5(1):61-71.

26. Ramalho-Santos J, Amaral S, Oliveira PJ. Diabetes and the impairment of reproductive function: possible role of mitochondria and reactive oxygen species. Curr Diabetes Rev. 2008:4(1):46-54.

27. Sameni HR, Ramhormozi P, Bandegi AR. Effect of ethanol extract propolis on histopathological changes and anti-oxidant defense of kidney in a rat model for type 1 diabetes mellitus. J Diabetes Investig. 2016;7(4):506-13.

28. Usman UZ, Bakar ABA, Mohamed M. Phytochemical screening and comparison of antioxidant activity of water and ethanol extract propolis from Malaysia. Int J Pharm Pharm Sci. 2016;8(5):413-5.

\section{Ready to submit your research? Choose BMC and benefit from:}

- fast, convenient online submission

- thorough peer review by experienced researchers in your field

- rapid publication on acceptance

- support for research data, including large and complex data types

- gold Open Access which fosters wider collaboration and increased citations

- maximum visibility for your research: over $100 \mathrm{M}$ website views per year

At $\mathrm{BMC}$, research is always in progress.

Learn more biomedcentral.com/submissions 